Portland State University

PDXScholar

\title{
Fallen Objects: Collaborating with Artificial Intelligence in the Field of Graphic Design
}

\author{
Harrison S. Gerard \\ Portland State University
}

Follow this and additional works at: https://pdxscholar.library.pdx.edu/honorstheses

Part of the Artificial Intelligence and Robotics Commons, and the Graphic Design Commons Let us know how access to this document benefits you.

\section{Recommended Citation}

Gerard, Harrison S., "Fallen Objects: Collaborating with Artificial Intelligence in the Field of Graphic Design" (2020). University Honors Theses. Paper 882.

https://doi.org/10.15760/honors.903

This Thesis is brought to you for free and open access. It has been accepted for inclusion in University Honors Theses by an authorized administrator of PDXScholar. Please contact us if we can make this document more accessible: pdxscholar@pdx.edu. 


\title{
FALLEN OBJECTS: COLLABORATING WITH ARTIFICIAL INTELLIGENCE IN THE FIELD OF GRAPHIC DESIGN
}

\author{
Harrison Gerard \\ An undergraduate honors thesis submitted in partial fulfillment of the requirements \\ for the degree of Bachelor of Science in University Honors and Graphic Design. \\ Thesis Advisor: \\ 2020
Portland State University \\ Elisabeth Charman
}

\begin{abstract}
In this paper, I discuss the creation, execution and reception of my digital art series Fallen Objects, in which I collaborate with a neural net to create pseudo-found objects. I explore how artists might collaborate with Artificial Intelligence obliquely, not by having the AI generate the images themselves, but instead generate input for the artists to make the images. While many artists are focused on training neural nets to replicate their own art inputs, I instead focus on working with an AI trained on external, easily-accessible data and creating images from the prompts it delivers. In this way, the AI works not as the artist but as the muse, delivering inspiration instead of finished pieces. Additionally, the objects present a sort of reflected look of mankind's collective psyche: the AI responds with things it feels are plausible from its training on human input, and by creating these objects, we can look into a sort of reflection of ourselves, as seen from a semi-objective third party.
\end{abstract}

\section{IntRoduction}

$\mathrm{W}$ e are watching the field of artificial intelligence and machine learning develop before our eyes. The results are constantly getting better; GPT2 was a news item for a while last year for its almost suspiciously good writing samples, and sites like thispersondoesnotexist.com create photo-realistic faces at will that are nearly indistinguishable from a real headshot.

Naturally, designers and artists want to get in on this too, and they have. Countless designers have done projects about generating new imagery, or playing around with interpolating source images. The problem is that these are just not very interesting. Currently, machine learning does best when it generates imagery from very similar source images. Human fac- es are great for this because human faces look very similar and (usually)follow the same set of rules: one nose, one mouth, two eyes, etc. But generating art is much harder because any piece is more than the sum of its parts. Feeding a machine a thousand masterpieces will not result in a great piece, but instead a surreal gray-ish square (fig. 1). The machine just cannot yet distinguish the qualities of a good painting that make it good. To put it another way, the machine is more focused on replicating brush strokes in a painting than it is on replicating objects in a painting. We are simply not at a point computationally to create this shift.

My idea was to come at this problem from the side: instead of having the machine gen- 
erate imagery, which it is bad at; it can generate writing, which it is good at. I used a neural net to generate prompts and instructions for various pieces, that I then carried out on my own.

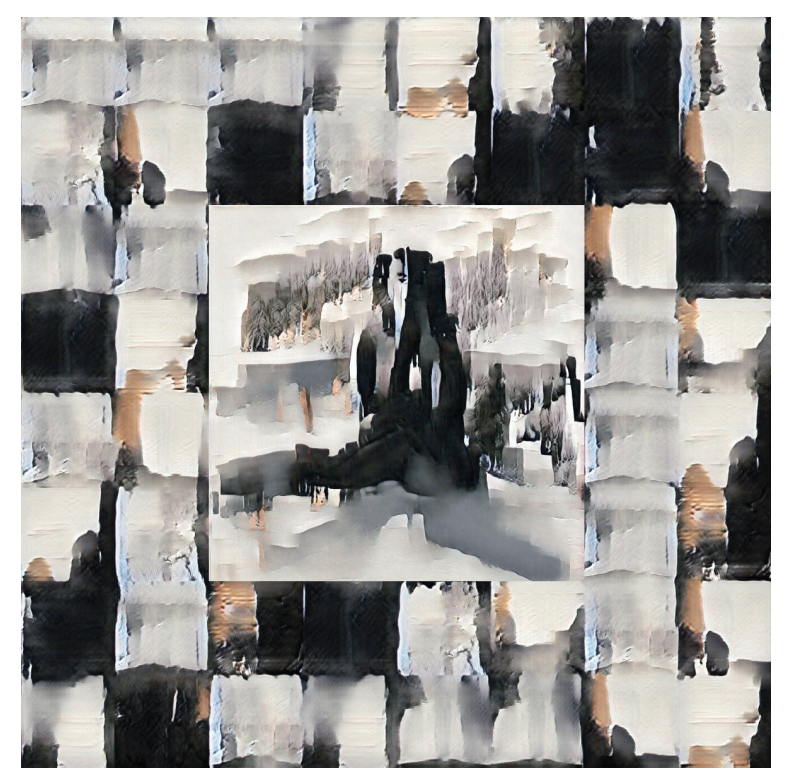

fig. 1: Om, Helena Sarin, 2018

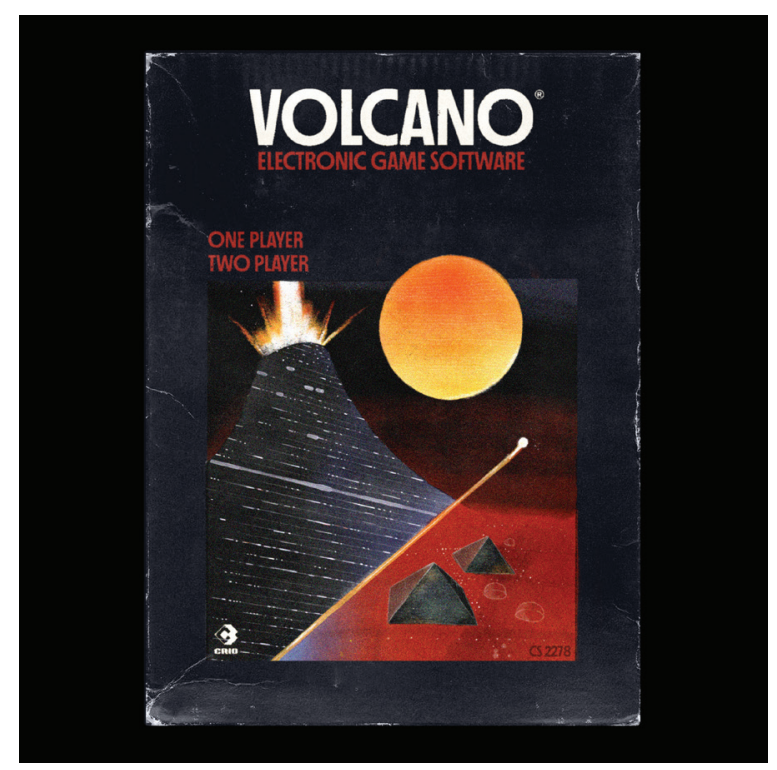

fig. 2: Volcano, Harrison Gerard, 2020

In the above example, a video game, I gave the AI the text: I went to the flea market and saw a table of old Atari 2600 video game car- tridges. My eyes immediately fixated on", and received: "Volcano", and my love for building video games with Will Eisner grew even more. I knew I had to build it. You might have read a few articles like this one before, so I'm going to try and keep the description short and sweet: Geodesic domes, domes or pyramids are designed as an efficient and elegant method of deploying frames and rendering the surface in a manner which is both robust and efficient. They are ideal for a wide range of applications where recreating the surface from the ground up can be cost prohibitive.

The neural net gave me colorful, yet cryptic prompts that I tried to rationalize as best as I could into plausible objects. Using both digital and physical techniques, I created a series of digital art objects that bring these prompts to virtual life.

Creating this project allowed me to bridge my interests in environmental storytelling, collaborative design, artificial intelligence, and world-building. It allowed me to create the first images of a reflection of the human psyche.

\section{ReseARCH}

One major inspiration for this project was the work of Emily Short, more specifically her works The Annals of the Parrigues and its successor, Tarot of the Parrigues. In Annals, Short generates a fictional travel guide in collaboration with various machine learning software. What is particularly interesting about Short's work is her unabashedness to collaborate with the machine directly. Most artists and creatives are determined to have the machine create the entirety of the generated piece itself, but Short instead treats the machine as a kind of collaborator, extrapolating on its ideas and editing its outputs. This leads to a superior result; there is both the unexpected creativity that comes from generated prose as well as the lucidity that a 
human editor can provide.

For the creation of the objects, and defining their aesthetic, I looked to Annie Atkins' book Fake Love Letters, Forged Telegrams, and Prison Escape Maps: Designing Graphic Props for Filmmaking. What inspired me about Atkins work is that although the objects all feel very unique, they seem to have a similar undercurrent running through them. Although they seem to live in their own worlds, Atkins' handiwork always shows through. There are also aspects of the work I found helpful from a more technical standpoint: for example,a section on aging papers, and various in-progress shots that show how she crafts things like rubber stamps or handwritten print.

Additionally, I spoke with Alden Rivendale Jones, an artist, researcher and programmer who is a research fellow at ITP NYU. We mainly discussed the integration of the frame story into the exhibit design, and how machine learning could most effectively be applied to my work. We also focused on the diegetic aspect of exactly what should and should not be revealed to the audience, and where to draw the line between fiction and fact throughout the exhibit. Alden also encouraged me to not fall into the pitfall of trying to make the AI a perfect fifty-fifty collaborator with me, but rather to work on creating the best work possible without worrying too much about exactly what we were both providing. This was a good piece of advice, and one I have often considered since. Alden also pointed me to the Fiction Practice | Onomatopee exhibit, which was inspiring both in terms of its content and overall design.

\section{Execution}

As it currently stands, I created 15 digital displays from 15 different prompts, with 21 separate, individual objects altogether. $\rightarrow$ 


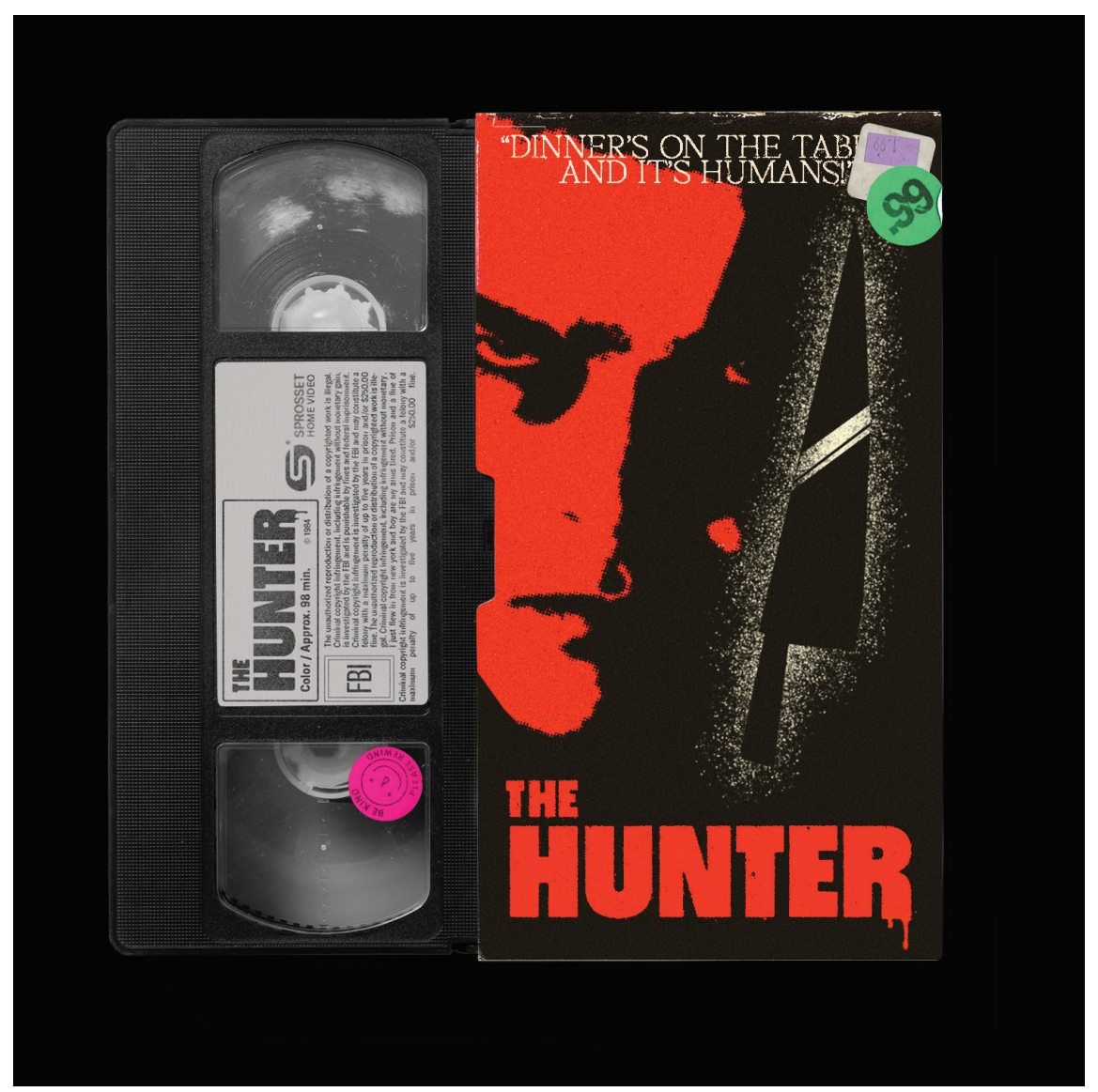

The Hunter, Harrison Gerard, 2020

Input: I was cleaning out my dad's attic when I found an old VHS called "

Output: The Hunter" i was stunned by the massive amount of carnage you see on the screen. The following day, when i saw that there was a new movie called "Monster Men" i just had to see it. Sadly, i did not know the author's name, but i knew who he was and i knew his work. Now, this film is more of a "VHS horror" with occasional horror thrown in. You will definitely not be sleeping in peace until you see the end. I made it 4 hours into the film and i am still fighting the desire to throw up. Then, there is another award winner with a lot of visceral action! Let's just say " 


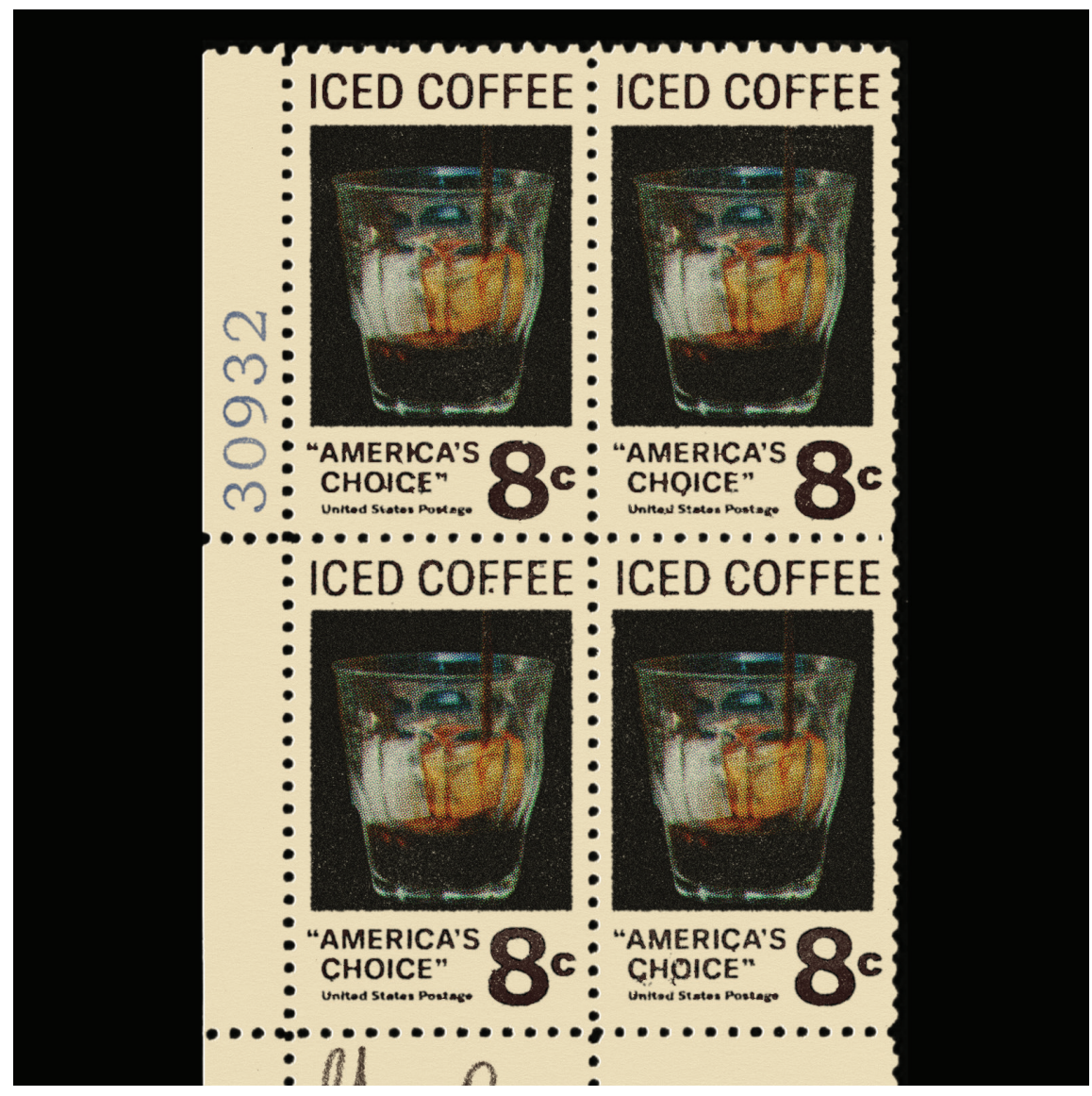

Input: I found a sheet of stamps, all themed around

Output: iced coffee. I liked the design, so I pulled it out and stamped it on my t-shirt. I decided to write my comments on the front and back of the stamps. I made my son print them out and give them to me, so that I would have them to remind me of what I want to do this weekend. That will be all. Thanks for reading. 


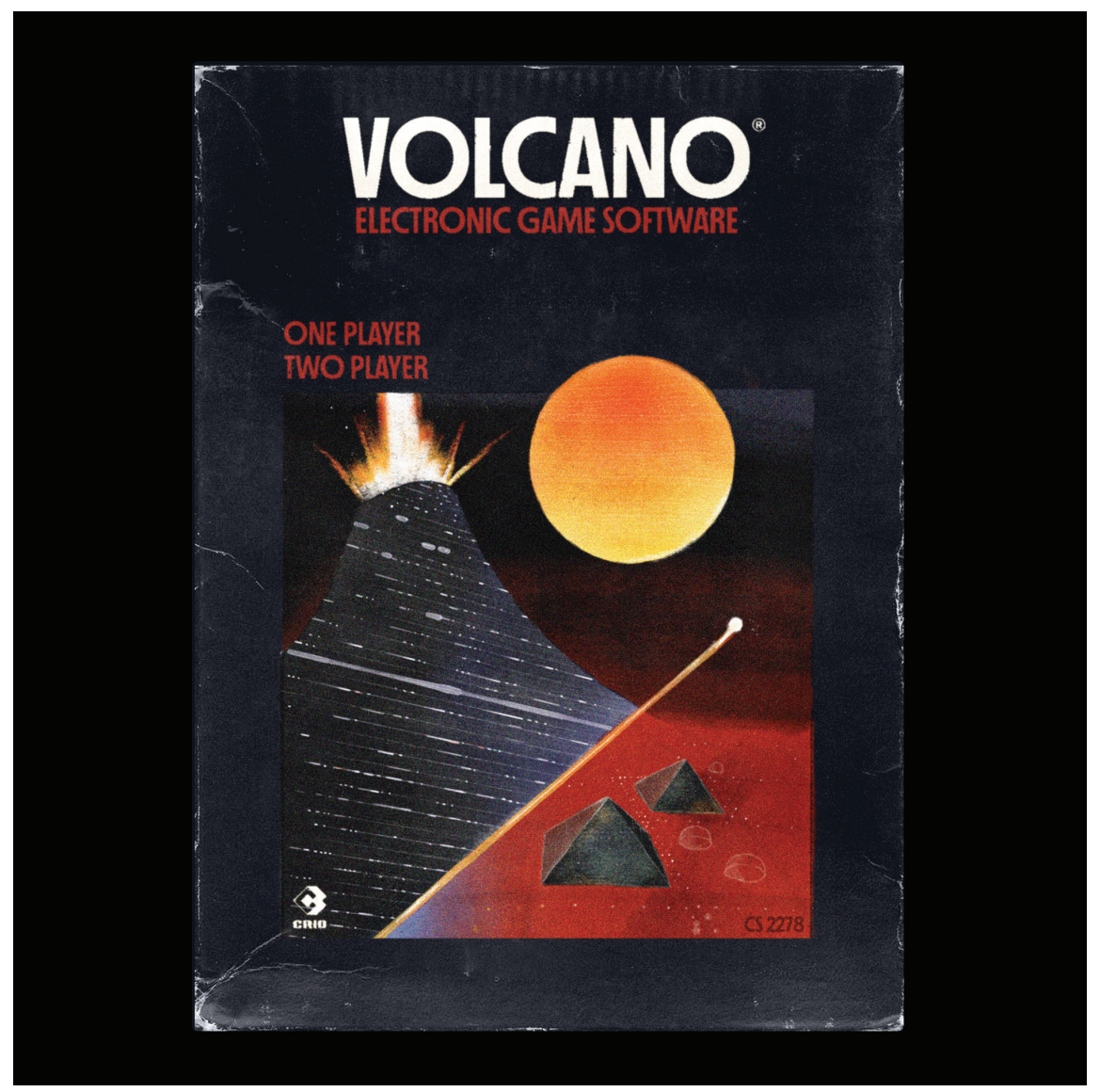

$\# \mathbf{3}$

Volcano, Harrison Gerard, 2020

Input: I went to the flea market and saw a table of old Atari 2600 video game cartridges. My eyes immediately fixated on "

Output: Volcano", and my love for building video games with Will Eisner grew even more. I knew I had to build it. You might have read a few articles like this one before, so I'm going to try and keep the description short and sweet: Geodesic domes, domes or pyramids are designed as an efficient and elegant method of deploying frames and rendering the surface in a manner which is both robust and efficient. They are ideal for a wide range of applications where recreating the surface from the ground up can be cost prohibitive. 


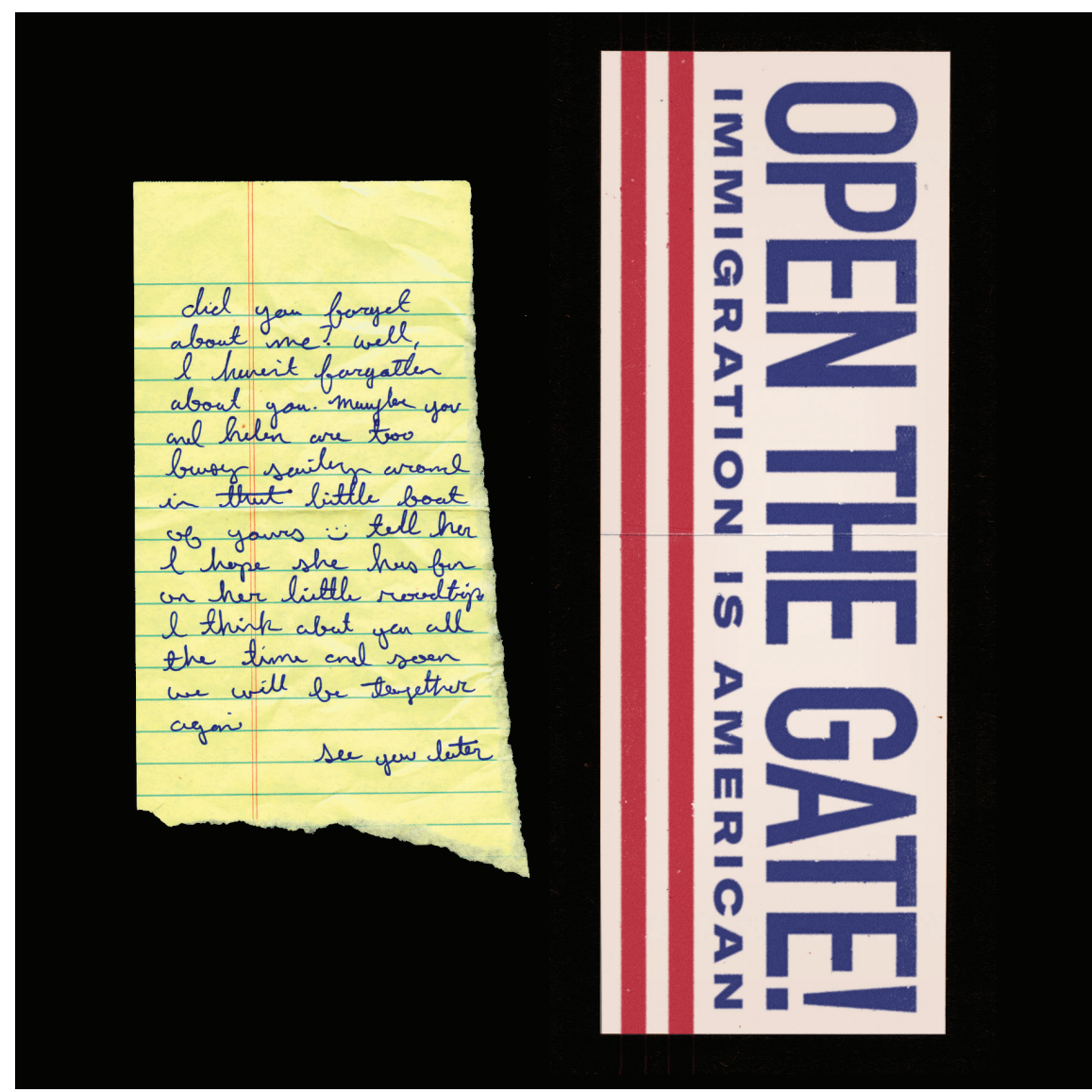

$\# \mathbf{4}$

Open the Gate!, Harrison Gerard, 2020

Input: I found a note someone tucked under my windshield wiper, talking about

Output: how it hadn't been so long since our last night on a boat. There's something I didn't tell them -- about all those road trips you did, that night and week earlier?

"I have to go now," I said.

That's my definition of perfect.

THEY STOLE MY TRIP CAMERA

Then I saw the bumper sticker: OPEN THE GATE! Open the gate! To add insult to injury, one of the boys next to me apparently stole my camera, but he's okay with it.

KEEP FOCUS ON THEM! 


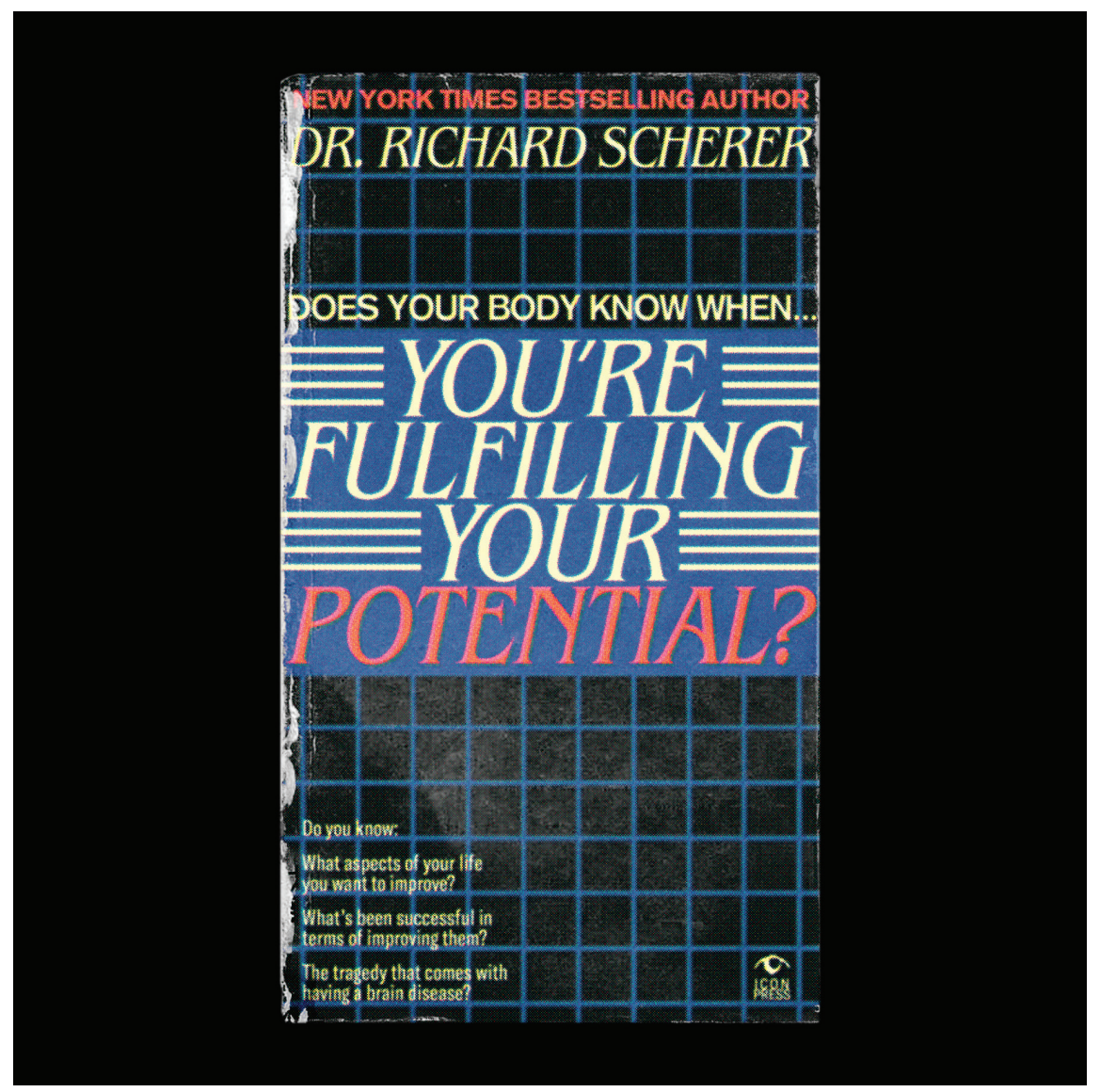

You're Fulfilling Your Potential?, Harrison Gerard, 2020

Input: Sitting on the table is a book called "

Output: Does Your Body Know When You're Fulfilling Your Potential?"' with Mr. Scherer of PsyChiatry, who specialized in psychological treatments. Mr. Scherer pointed out to me that there are two basic questions that patients must answer: What aspects of their lives do they want to improve? And what has been successful in terms of improving those aspects?

Dr. Scherer said a patient must be acutely aware of "the tragedy that comes with having a brain disease," in his example of diabetes. 


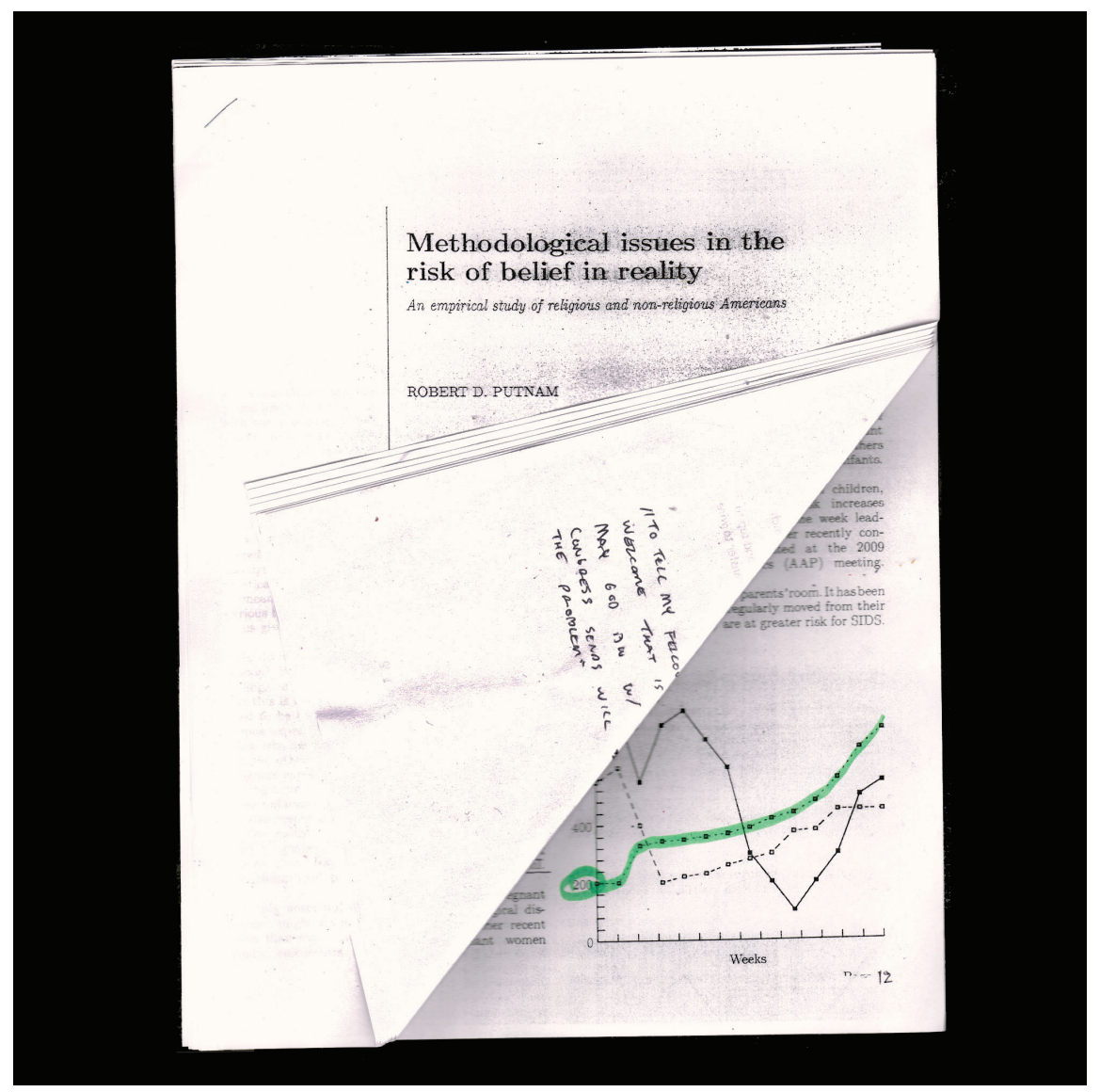

Input: I had found an academic paper called "

Output: Methodological issues in the risk of belief in reality: An empirical study of religious and non-religious Americans" and found it very interesting. It was actually very informative, even though I admit it was a very short paper.

But the authors of that paper in fact had a very important design flaw, which was actually on page 12 of the paper. You see, they ran three different kinds of analyses, which they basically tried to do three different types of experiments. All three different types of analyses should have gone a lot better. 


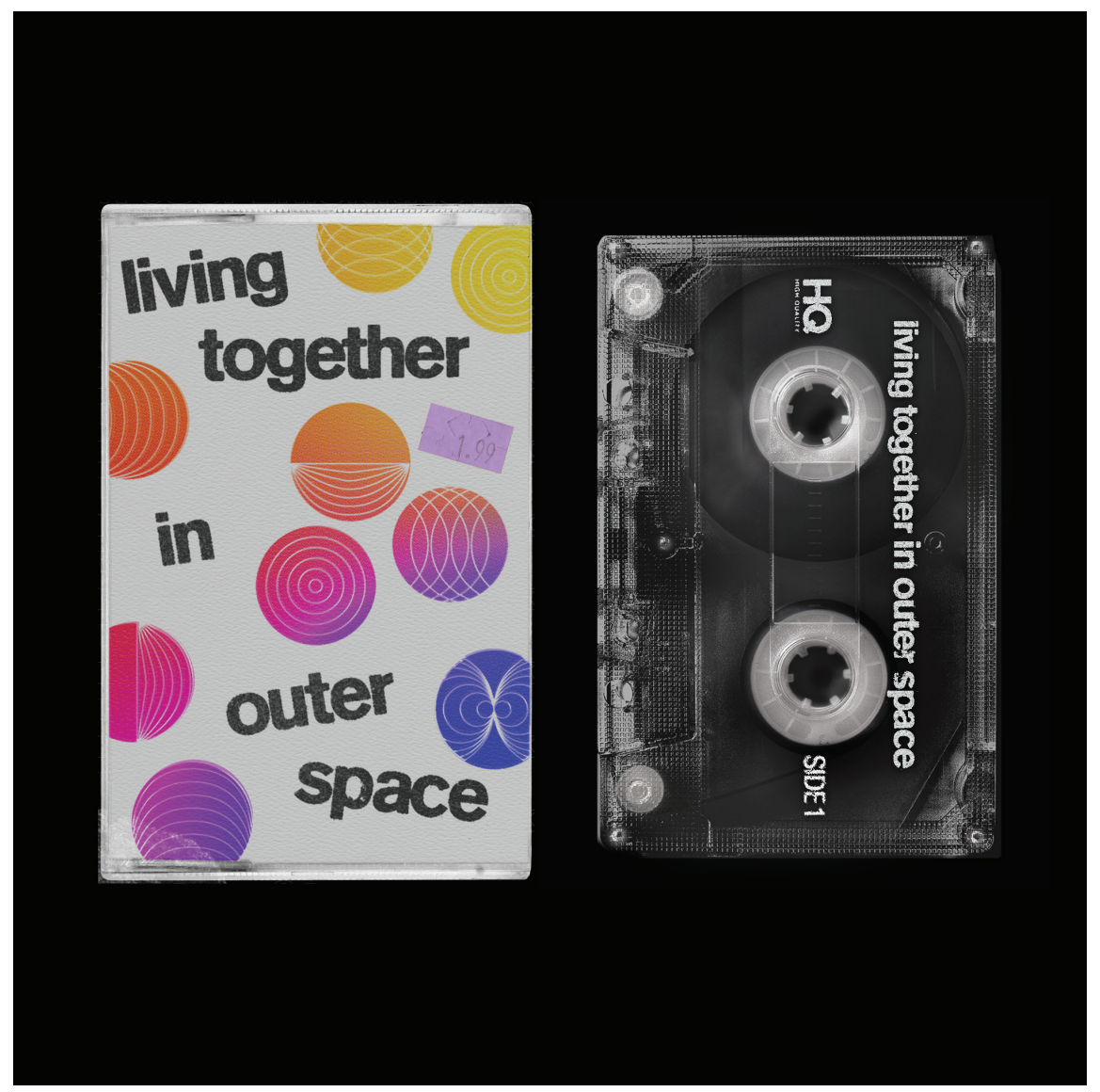

$\# \mathbf{7}$

Living Together in Outer Space, Harrison Gerard, 2020

Input: He handed me a cassette. It was titled

Output: Living Together in Outer Space, and it was nothing like anything I'd heard before. It was so odd and unique that I went home to listen to it on repeat. "I remember I listened to that thing a lot in the fall and winter of 1969 when I was living in Southern California, 'cause I'd come back from Berkeley and move to Culver City to work at The Beachcomber's, which was one of the first record companies I did music for. The following spring I sent out the tapes I'd sent him to various artists and writers, and they were up everywhere, and then after a few weeks, they started getting some kind of cold response from other writers, but I was hanging on, 


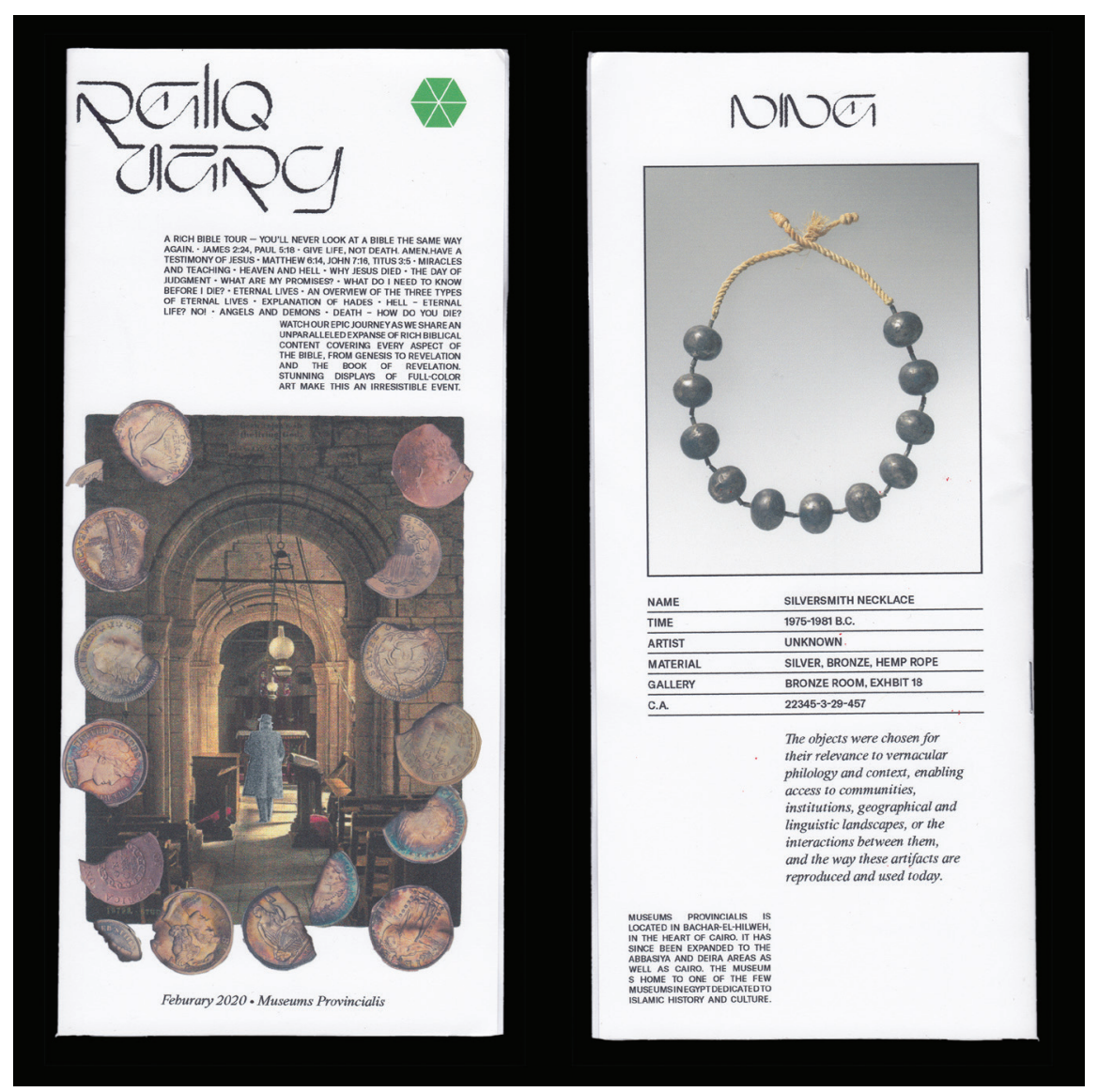

$\# 8$

Reliquary, Harrison Gerard, 2020

Input: On the ground was a guide to a museum exhibit called

Output: "Reliquary." A person slowly walked down a row of coins, all of which looked like they had been taken out of the time machine and incinerated.

The main attraction was a book that said "A Rich Bible Tour - You'll never look at a Bible the same way again." The guide didn't have a back-story for the Bible as being the inspiration for popular culture. In the firehouse was two big silver chains, each complete with a bronze gem. Not going to waste time to pick one up, I went straight for the coins, seeing that it would be easier. The guide said that each chain was really about $\$ 7,000$. 


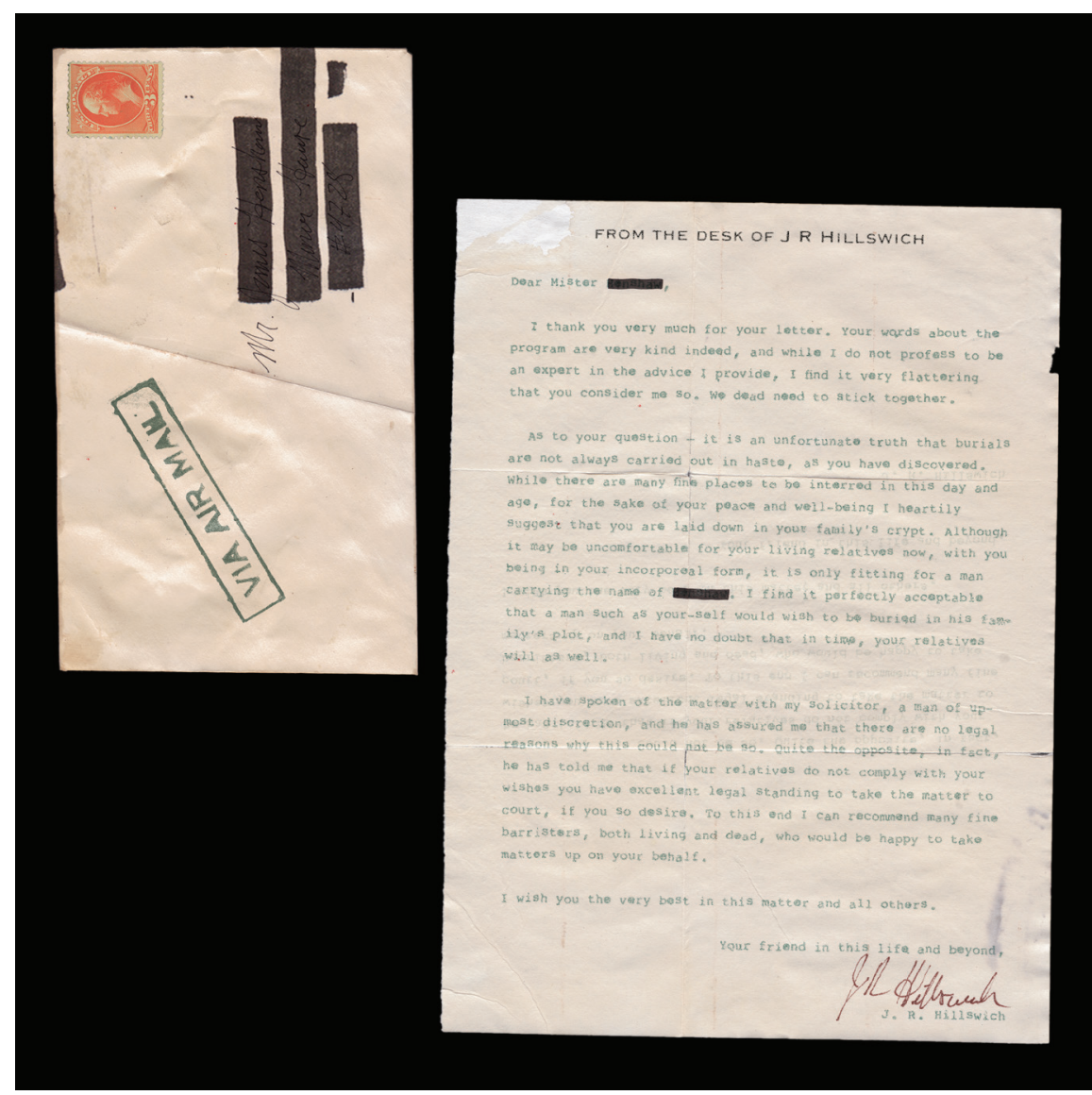

Family Crypt, Harrison Gerard, 2020

Input: I had found a letter addressed to

Output: , who had passed away about five years ago, and had written in answer to his questions as to where to be buried. After reading it I expressed to him the desire to be buried in the family crypt, which he had left as a care to his uncle, the late . He had left it to me to find out if it would be proper. At the time of his passing I had never told the truth, but knowing I had a great respect for him and knew he would like to be buried in the family crypt I thought it right I should find out what the law and custom was. I wrote my letter to him and asked his permission. He signed it and he died 


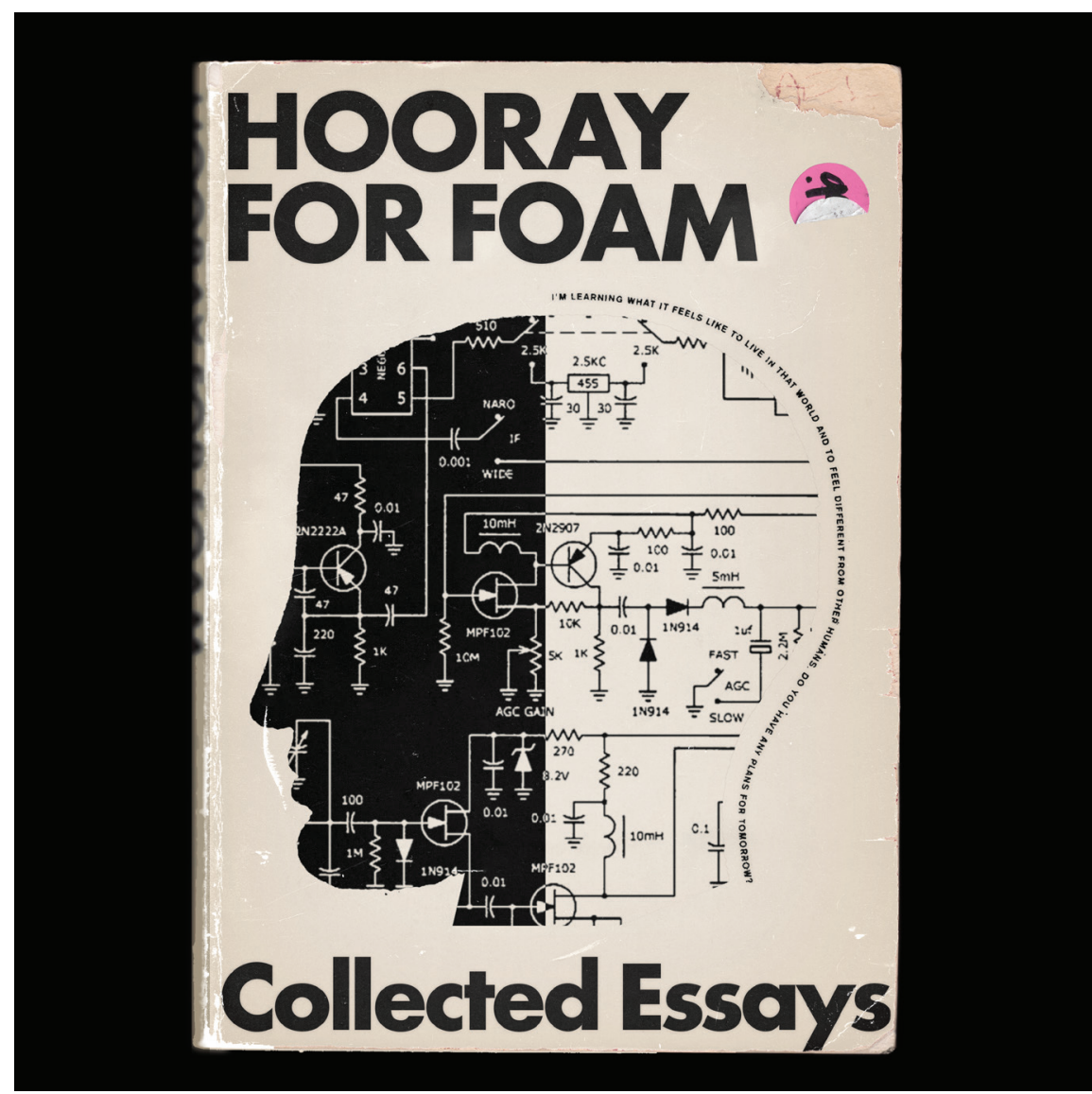

Hooray for Foam, Harrison Gerard, 2020

Input: On sale was a book called "

Output: Hooray for Foam," a collection of essays about the history of mind control research.

"I'm learning what it feels like to live in that world and to feel different from other humans," the book says in its cover text. "Do you have any plans for tomorrow?"

The book includes essays that talk about several examples of scientists and intelligence agencies developing and testing various concepts of mind control for many decades.

"Hooray for Foam," for example, is called "The Craft of Thought Control." It notes that in the first days of the 


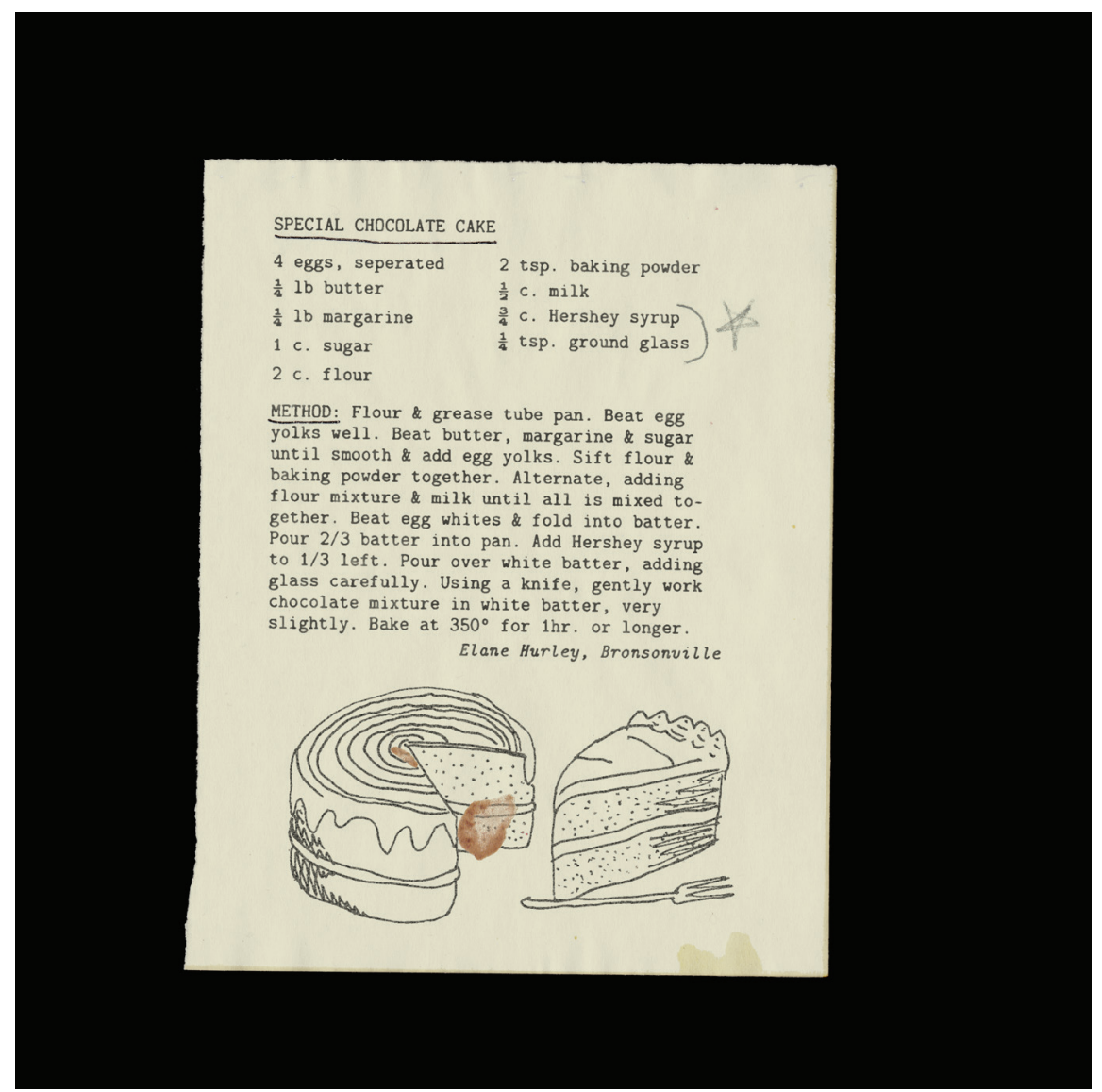

A Mysterious Dish, Harrison Gerard, 2020

Input: I had found a slip of paper, on which was written a recipe for

Output: a mysterious dish, which I started to prepare, for which I was well provided with all the equipment.

"Did you eat this breakfast, sir? I am pleased to see you in good health." said the innkeeper, as he handed me a glass of milky tea.

"No, sir. But I got you that strange chocolate cake, which you must have for breakfast tomorrow morning," said I.

"That's not possible, sir. This isn't 'kiddie' chocolate."

I drew up my napkin and pointed to the label on the top.

"Kiddie chocolate is very special stuff, sir. 


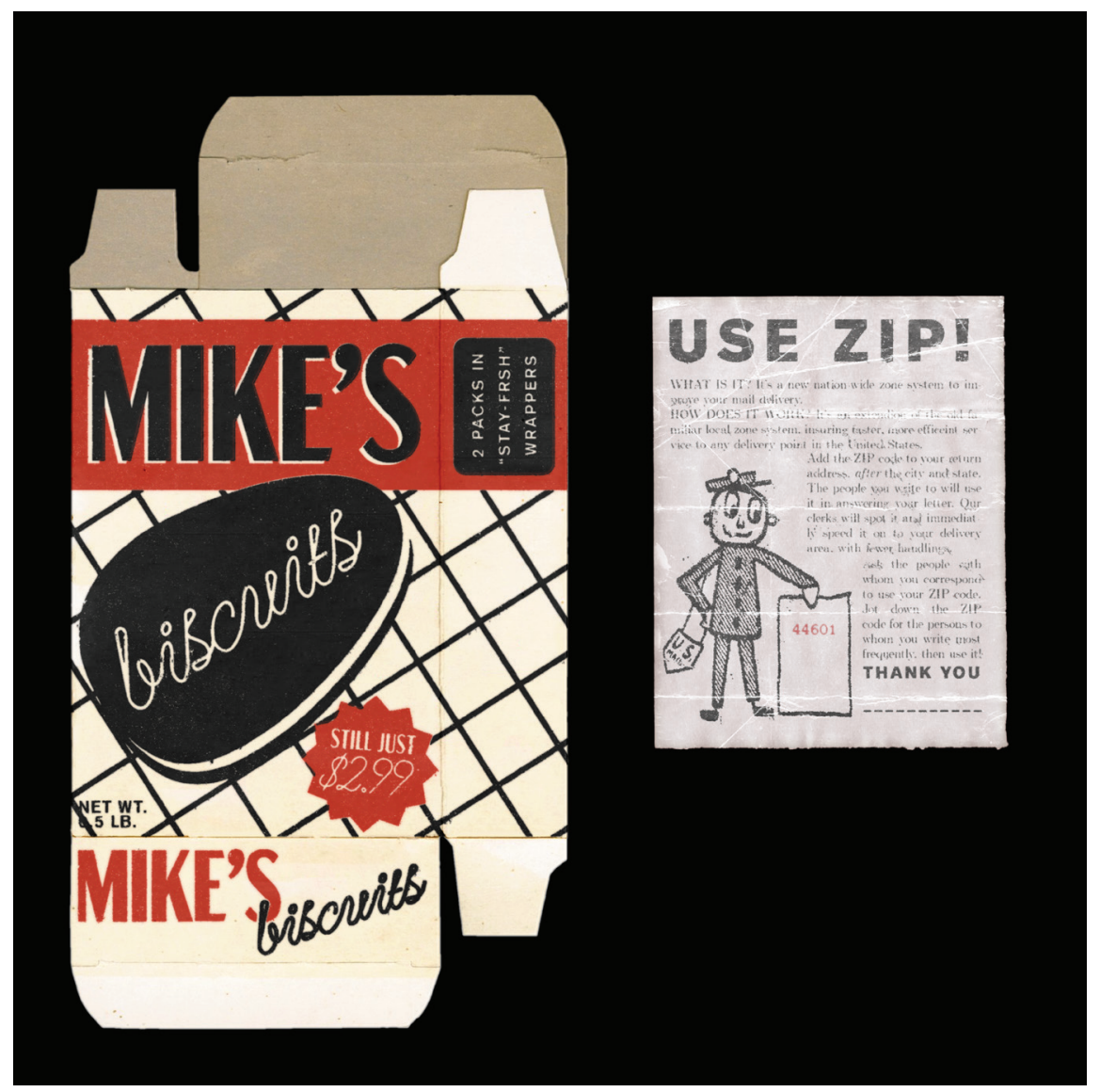

\#12

A Very Unusual Looking Label, Harrison Gerard, 2020

Input: I pulled up a loose floorboard, revealing

Output: a sliver of blue box on top. It was almost 20 feet long, with a case of Mike's biscuits inside. mike found the first, egg-shaped biscuit on the passenger seat. It had a red, shiny wax paper to it, and a "very unusual looking' label. It said, "\$2.99" and had a note underneath, with the name of the town and the postal code. This was supposed to be a candy bar of some sort, which turned out to be a British Quaker's guide. It would be about 6.5 inches long, 3.75 inches wide and about 3 inches thick. It wasn't the candy bar 


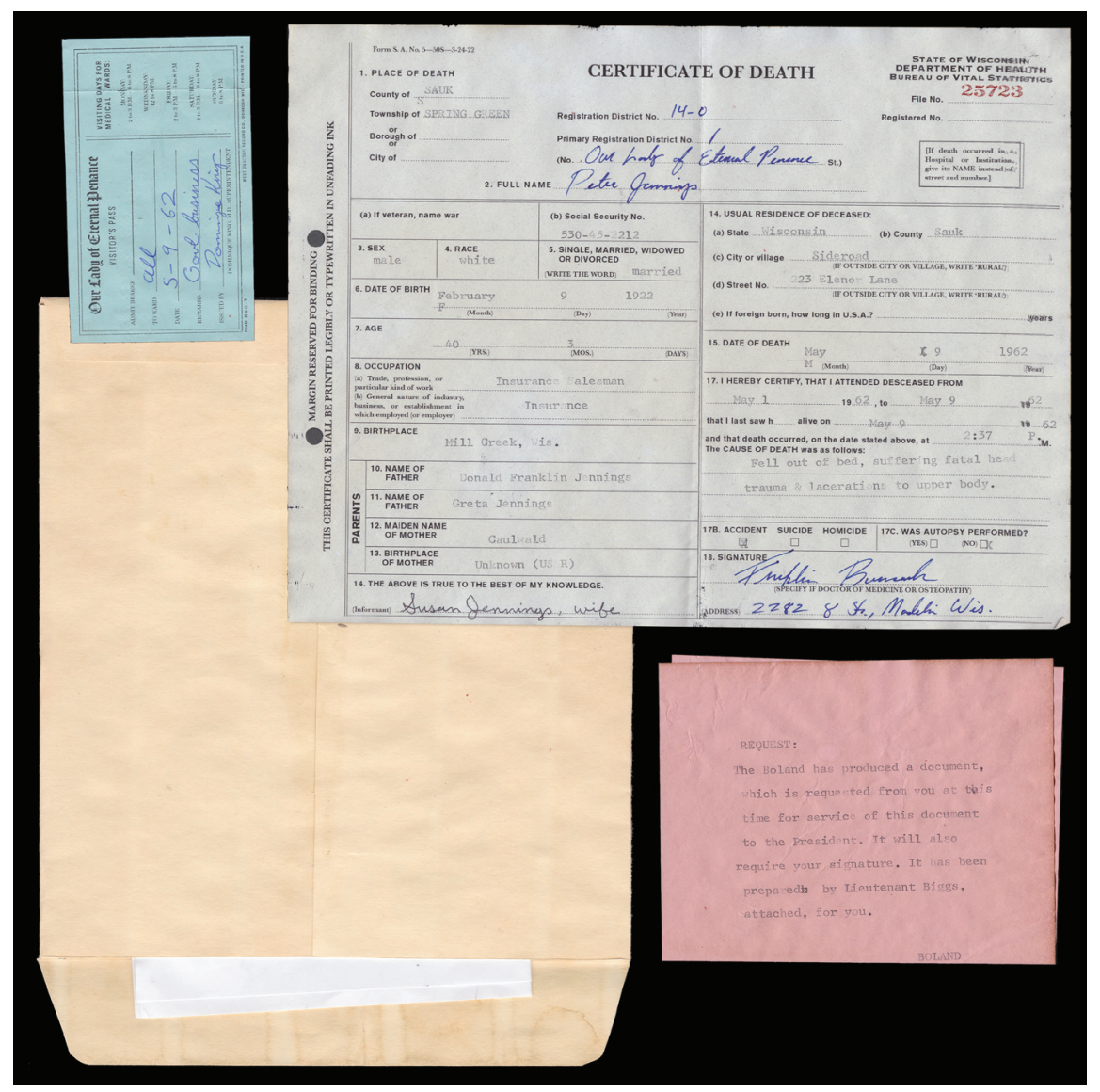

A Kind of Pass, Harrison Gerard, 2020

Input: He handed me an envelope. Inside was

Output: a kind of pass and certificate. Inside this there was a request to read and sign a memo. The request seemed vague. I read it, and it stated: "The Boland has produced a document, which is requested from you at this time for service of this document to the President. It will also require your signature. It has been prepared by Lieutenant Biggs, attached, for you."

I signed it, and then I handed it to a young officer, Mr. F. H. Freeman, and he read it aloud. I thought it would not do for the imprimatur of the President to be invoked, and also thought the document was so much out of the way that I could 


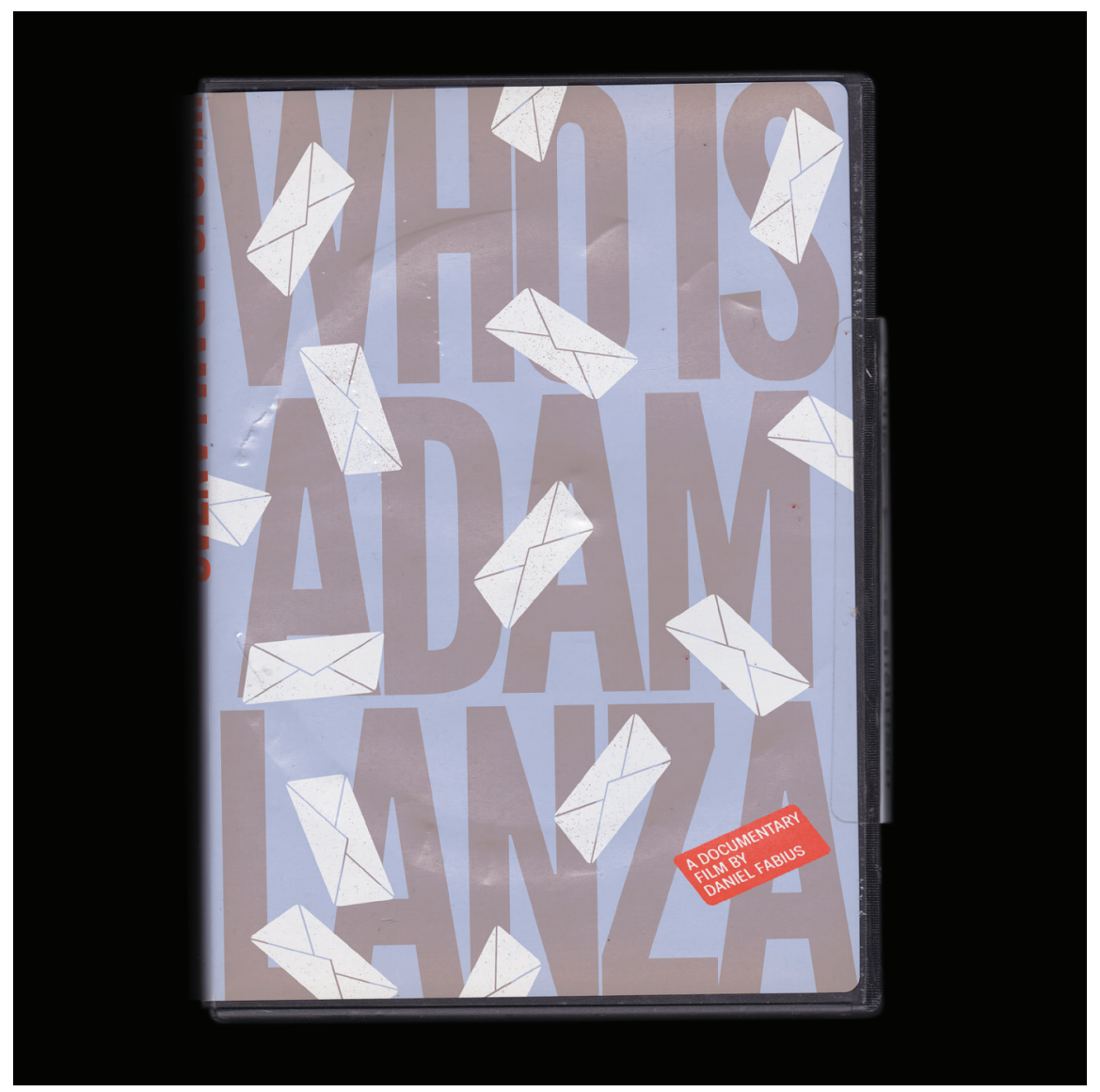

Who is Adam Lanza, Harrison Gerard, 2020

Input: A dvd case for a movie called

Output: "Who is Adam Lanza?"

"We have seen the families we've come across first hand and then when you get that one letter from somewhere like that, it's like, 'Oh, okay, now that's why I chose to give this to you.' It hits you like a ton of bricks."

In December 2012, Fabius wrote a letter to a friend who used a pseudonym in order to get her child out of a school in South Lanarkshire. Fabius' letter brought to light the existence of another letter that was said to have been written by Adam Lanza to Nancy Lanza, Nancy's husband. The note allegedly stated that his parents were "more concerned about what [Adam] 


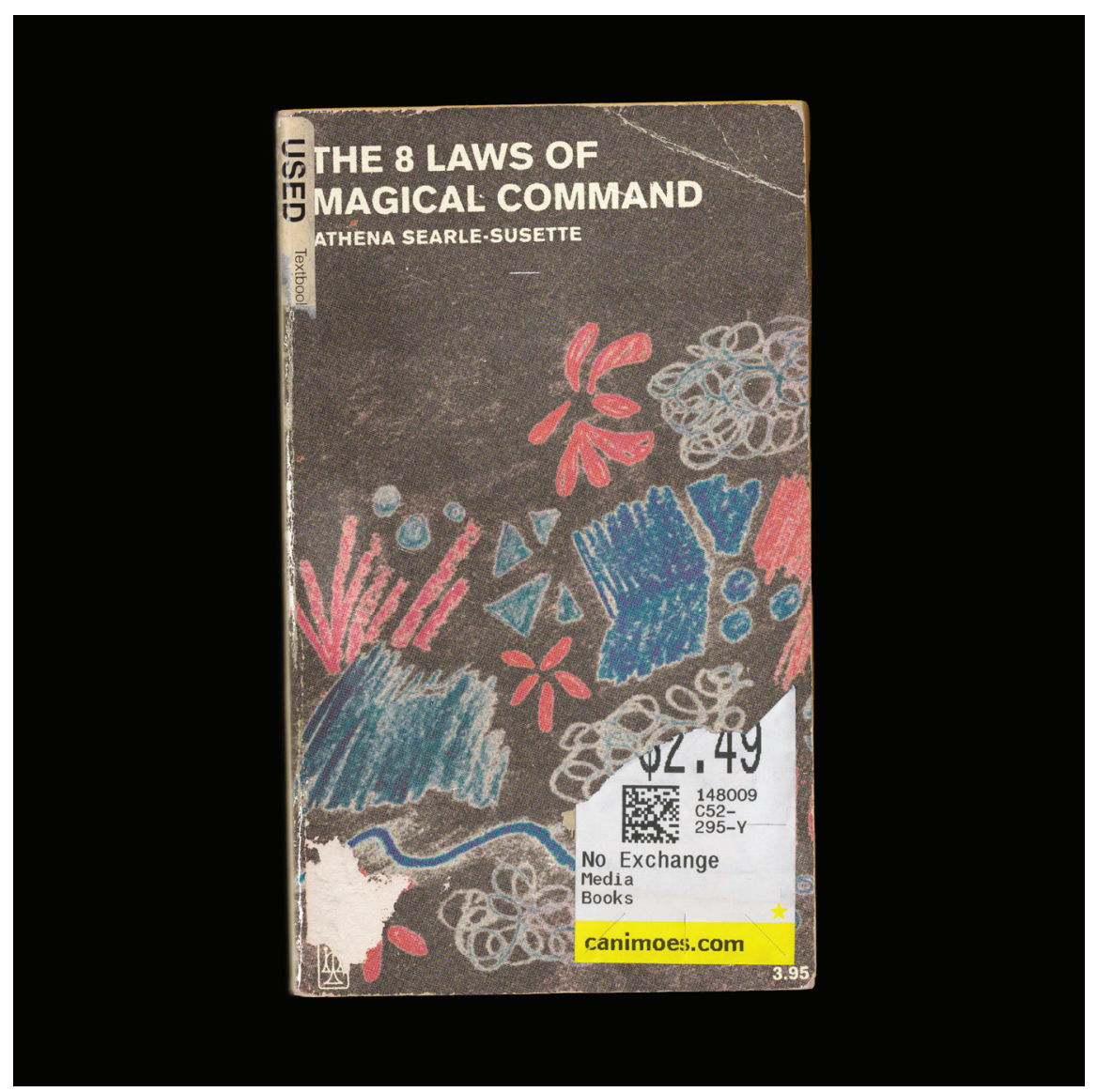

Canimoes.com, Harrison Gerard, 2020

Input: I got a book on sale called

Output: The 8 Laws of Magical Command. I have ordered it and will definitely use it again." "I recently purchased C2 from Canimoes.com. I have yet to use it but am very impressed with their quality. I'll be sure to give it a big thanks for their great service." "I purchased a Jay Dee page from Canimoes.com. It was extremely well done and perfect for my needs. I haven't used it yet, but will. So far, so good." "I'm considering Jay Dee online products. They're delivered quickly, well made, and do a good job of describing what you want. From my first purchase, Jay Dee has been a 


\section{Execution (Cont.)}

For this thesis, I had certain rules that I set for myself. They were:

- That while I could generate as many responses from a prompt as I wanted, I would not alter the text output by the AI. (This was the hardest of the rules, but also the most important, in my opinion. I was often tempted to tweak the machine's text to make it easier on myself, but I refrained.)

- I would incorporate as much of the AI's description as possible, although exactly what I included would always be at my discretion. (Throughout the project there was often extraneous info that I could not find a home for without damaging the lucidity of the object. Since the AI would tend towards dream-like language, I would often have to play editor, choosing the most interesting pieces to focus on and discarding info that did not fit.)

- That every object would be 'scannable', that is, small and flat enough to fit on a flatbed scanner. (This was to ensure a sense of visual cohesion between the pieces. By encapsulating each object in a black field they feel discrete and physical. Additionally, the scanned look of the pieces gives a sense of realism to the objects as well.)

- That every object should feel as real and as well-designed as possible. (To this end, the majority of my time on each object was to make it feel as real and lived-in as possible. I did not want them to feel Photoshopped or obviously artificial. The most flattering response I got was from one of my classmates who told me that she saw an object on Instagram and thought that they were just "beautiful scanned documents", and only realized they were artificial when she read the description.)

These rules served as scaffolding for the project, allowing me to play off them and find ways around them creatively, as I illustrate in the example below.

I found out quickly that the best way to make things look real was often to actually make them. I quickly went from spending all my time on Photoshop to spending my time soaking paper in coffee and drying it in my oven.

\section{Process}

The most intensive display was $A$ Kind of Pass, which involved making four different objects to complete one prompt. I will describe my process in creating this display as an example of my typical process on this project.

For each display, once I choose the prompt to use, I sit down and make notes of the crucial details. For 'a certificate', I knew I wanted to include five things: an envelope, a memo, a pass, a certificate and a note.

After this, I think of how these objects will be executed. When I first read the prompt for a certificate, I had the idea of the pass being an old hospital visiting pass. From this, I made my other decisions -- the certificate would be either a birth certificate or death certificate from the hospital, the note was written for me and the memo would be hidden in the envelope.

I do a lot of visual research for each display. For 'a certificate', I started gathering reference imagery of hospital passes and birth and death certificates. I found the look of death certificates to be more interesting than the look of birth certificates, so I chose to go down that route. I also thought that the mor- 
bidity of a death certificate was more interesting, and that it provided the viewer with a more interesting narrative.

As I started to make my decisions as to how I would execute the pieces, I started to form a narrative as well. I try not to be too heavy-handed in the story telling, however; I think it is important to let the viewer draw their own conclusions and write their own ending, so to speak. For 'a certificate', the military language and title of "The Boland" conjured up imagery of spies and secret documents, which I liked.

I began by making the death certificate. With my reference in hand, I began the process of building out the form on Adobe Illustrator. I chose aspects of various certificates I had found that I liked and combined them, paying close attention to the kinds of typefaces commonly used, and how items were spaced.

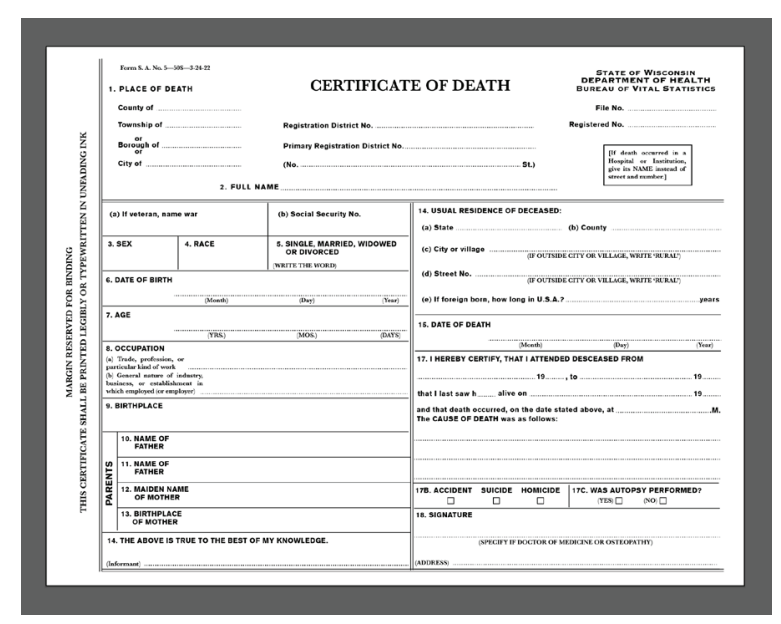

fig. 3: 'clean' death certificate

With the form done, I moved on to the paper itself: I soaked a piece of blue paper in a weak coffee solution, then wiped it off with a dishtowel. This does a remarkably good job at making paper look older, although the drawback is that it often dries in a crinkly, waterlogged way. To combat this, I misted the paper with water and ironed it between two cotton dishcloths, mostly flattening it.
I then printed the certificate onto the paper with an inkjet printer. There is no perfect way to do this: the ink is water soluble so it must be printed after it is aged, or it will smear; but the act of distressing the paper makes it hard for the printer to actually print on, often leaving smears of ink or double-printing. For this piece, I was fine with any printing mistakes as it lent to the realism of the piece. Often, the obvious perfection of a piece is a dead giveaway that it made digitally.

I folded the certificate and printed the type with a borrowed typewriter. In one of my reference images, half the type was handwritten and half was typed, which gave it a look I admired. I did likewise, thinking of what text would be theoretically typed by a secretary and what would be handwritten by the doctor. One of the hardest parts of this project was trying to get my handwriting to look plausibly different for when a document was written on by multiple people.

With the certificate filled out, I scanned the document and brought it into Photoshop. Here, I added the stamped number in the corner. I would prefer to do the stamp in real life, just like the rest of it, but I could not get access to the materials I needed to do so.

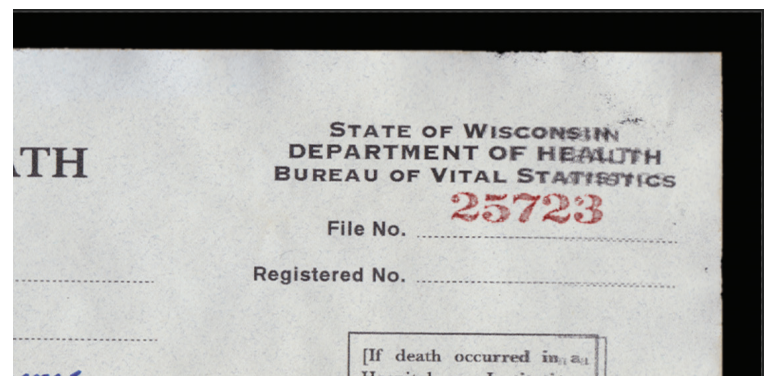

fig. 4: stamped number

I then moved onto the pass, which followed the same steps as the certificate; and then the note, which was easier as I only needed to type it out.

For the envelope, I was unable to get one due 
to Covid-19, so I created one myself by aging, cutting and gluing a manila folder. The memo would remain secret inside, with just the top of it poking out, I decided.

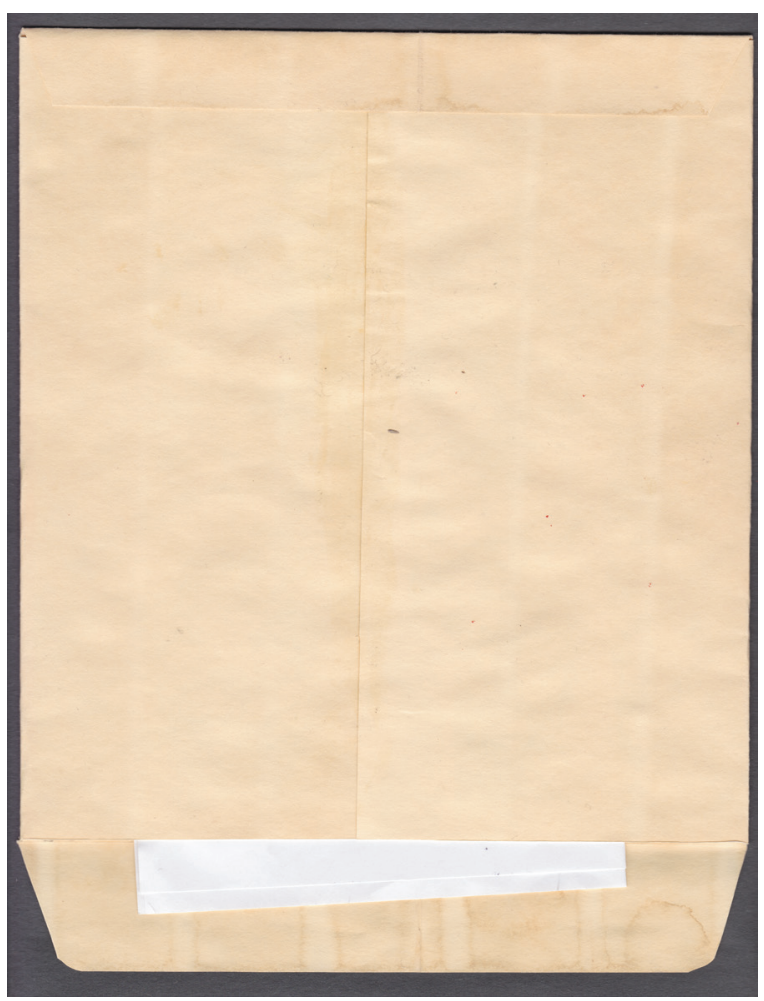

fig. 5: crafted envelope

With all the pieces done I scanned each separately and combined them in Photoshop. This was more-or-less the process I used for every display: collecting reference, doing by hand what I could and digitally what I could not, aging and distressing the pieces for realism and scanning them all on my flatbed scanner.

The process of 'a certificate' took four days, which was by far the longest of any of the pieces. Most took about a day's worth of work to complete.

I distributed all the objects on my personal instagram, the collection building over the course of a month. With this initial round of objects complete, they will be added to an archival website where they can be seen without the limits that Instagram places on them (aspect ratio, image quality, etc.).

I posted each piece as a series of images, to be swiped through by the user: the first was always the object completely encapsulated in a black field, then a handful of close-ups to show details and texture, and finally an image of the text given to me by the AI.

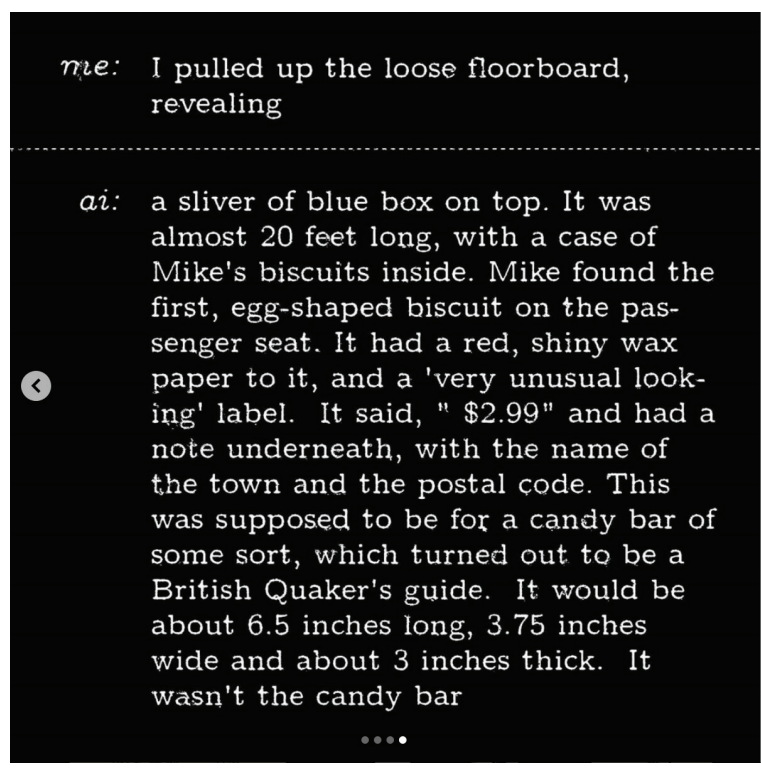

fig. 6: example of a text slide

Although each object is designed to stand alone, together they become more than the sum of their parts: they tell a collective story, encouraging the viewer to make connections between pieces and weave their own narrative. I purposefully reused some elements between pieces, like logos and company names, to link the series together and give an overall sense of cohesion.

The Instagram distribution of the pieces allowed my page to become a sort of virtual gallery, and also provided an easy, low-barrier-of-entry way for viewers to respond directly to the works and to me as well. Viewers' feedback and comments allowed me to alter the course of future objects, adding a perfor- 
macne art element to the work as a whole. In the spirit of Dickens, Dumas and other episodic creators, the feedback I recieved was able to be immediately applied to the next section of the work. I encouraged viewers to give me prompts to feed the AI, and hid their names in the works in various ways.

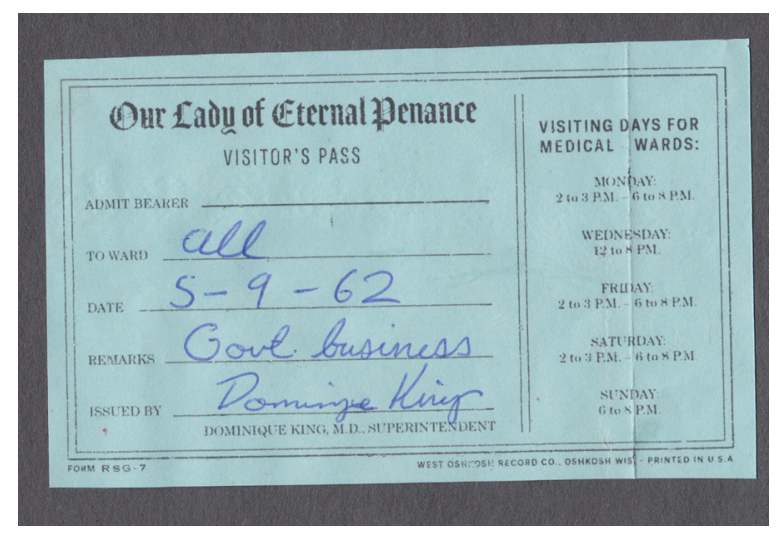

fig. 7: Visitor's Pass

In figure seven, above, Dominique King is the name of a viewer that I included in the work.

The innately digital nature of Fallen Objects lent itself well to the digital distribution of the works, and provokes questions on exactly what a gallery can be, and where the lines of collaboration should be drawn.

\section{Conclusion}

Fallen Objects demonstrates a new way of collaborating with AI that is easily accessible for artists and designers. By shifting the focus from "AI as creator" to "AI as collaborator," the best of both machine and human can be combined. The AI takes on a role of co-creator, producing ideas at-will that the designer can then choose from and edit.

The language model used in Fallen Objects, GPT-2, was trained off of 40 gigabytes of English text pulled from the internet. The objects it suggests are remarkable in that the majority of them seem believable, and by making them 'real' they provide an inter- esting insight into the kind of things humans like to produce. Each object is a facet of a reflection on the human psyche, an impostor suggested by an outside party.

The objects become a reflection of the collective human psyche, all of them possible but unfulfilled. Non-existent books and movies are suggested so plausibly that most viewers' responses could be boiled down to one comment: "I can't believe this isn't real".

By exploring what makes an object real, we are able to examine our own reflection more objectively. Since GPT-2 was trained on internet text, the responses it gives are reflections of the content it was fed. By making these prompts material, viewers are able to encounter something from their own digital subconscious. The viewer, encountering fake objects made to look real, is able to scrutinize them for both their appearance and their content. It is up to the viewer to decide what part of them is truly artificial.

Fallen Objects walks alongside other works as the first steps of a new way of working with Artificial Intelligence. 


\section{BIBLIOGRAPHY:}

[1] Emily Short-Five Strategies For Collaborating With A Machine [PROCJAM 2016]. (2016, October 27). https://www.youtube. $\mathrm{com} /$ watch? $v=$ narjui3em1k\&feature $=e m b \_$title

[2] Kugel, P. (1981). Artificial Intelligence and Visual Art. Leonardo, 14(2), 137-139. JSTOR. https://doi.org/10.2307/1574409

[3] Radford, A., Wu, J., Amodei, D., Amodei, D., Clark, jack, Brundage, M., \& Sutskever, I. (2019, February 14). Better Language Models and Their Implications. OpenAI. https://openai.com/ blog/better-language-models/

[4] Short, A. E. (2012, August 30). San Tilapian Studies (a casual narrative entertainment for 30-40 players). Emily Short's Interactive Storytelling. https://emshort.blog/2012/08/30/san-tilapian-studies-a-casual-narrative-entertainment-for-30-40-players/

[5] Atkins, A. (2020). Fake Love Letters, Forged Telegrams, and Prison Escape Maps: Designing Graphic Props for Filmmaking. Phaidon Press.

[6] Pestana, M., \& van der Veer, J. (n.d.). Fiction Practice / Onomatopee. Retrieved March 7, 2020, from https://www.onomatopee.net/exhibition/fiction-practice/ 